\title{
Analysis of C. elegans NR2E nuclear receptors defines three conserved clades and ligand-independent functions
}

\author{
Katherine P Weber, Christopher G Alvaro, G Michael Baer, Kristy Reinert, Genevieve Cheng, Sheila Clever and \\ Bruce Wightman*
}

\begin{abstract}
Background: The nuclear receptors (NRs) are an important class of transcription factors that are conserved across animal phyla. Canonical NRs consist of a DNA-binding domain (DBD) and ligand-binding domain (LBD). While most animals have 20-40 NRs, nematodes of the genus Caenorhabditis have experienced a spectacular proliferation and divergence of NR genes. The LBDs of evolutionarily-conserved Caenorhabditis NRs have diverged sharply from their Drosophila and vertebrate orthologs, while the DBDs have been strongly conserved. The NR2E family of NRs play critical roles in development, especially in the nervous system. In this study, we explore the phylogenetics and function of the NR2E family of Caenorhabditis elegans, using an in vivo assay to test LBD function.

Results: Phylogenetic analysis reveals that the NR2E family of NRs consists of three broadly-conserved clades of orthologous NRs. In C. elegans, these clades are defined by $n h r-67$, fax-1 and $n h r-239$. The vertebrate orthologs of nhr-67 and fax-1 are TIx and PNR, respectively. While the $n h r-239$ clade includes orthologs in insects (Hr83), an echinoderm, and a hemichordate, the gene appears to have been lost from vertebrate lineages. The C. elegans and C. briggsae nhr-239 genes have an apparently-truncated and highly-diverged LBD region. An additional C. elegans NR2E gene, nhr-111, appears to be a recently-evolved paralog of fax -1 ; it is present in C. elegans, but not C. briggsae or other animals with completely-sequenced genomes. Analysis of the relatively unstudied nhr-111 and nhr-239 genes demonstrates that they are both expressed — nhr-111 very broadly and nhr-239 in a small subset of neurons. Analysis of the FAX-1 LBD in an in vivo assay revealed that it is not required for at least some developmental functions.
\end{abstract}

Conclusions: Our analysis supports three conserved clades of NR2E receptors, only two of which are represented in vertebrates, indicating three ancestral NR2E genes in the urbilateria. The lack of a requirement for a FAX-1 LBD suggests that the relatively high level of sequence divergence for Caenorhabditis LBDs reflects relaxed selection on the primary sequence as opposed to divergent positive selection. This observation is consistent with a model in which divergence of some Caenorhabditis LBDs is allowed, at least in part, by the absence of a ligand requirement.

\section{Background}

The nuclear receptors (NRs) constitute a class of transcriptional regulators that are conserved throughout the animal kingdom, where they function in a wide variety of physiological and developmental roles, including metabolic regulation, xenobiotic defense, and development [1-4]. Archetypal NRs have a DNA-binding domain (DBD), which contains two $\mathrm{C}_{4}$ zinc fingers and

\footnotetext{
* Correspondence: wightman@muhlenberg.edu

Biology Department, Muhlenberg College, Allentown, PA 18104, USA
}

mediates binding to specific DNA sequences and receptor dimerization, and a more C-terminal ligand-binding domain (LBD), which may bind a lipophilic ligand and functions in dimerization, nuclear localization, and transcriptional trans-activation. Across the animal kingdom, amino acid sequence similarity is strongly conserved in the DBD, and more weakly conserved in the LBD. The majority of NRs that have been identified on the basis of phylogenetic sequence relationship have no known ligand, despite having a recognizable LBD and are sometimes referred to as "orphan receptors" [1].

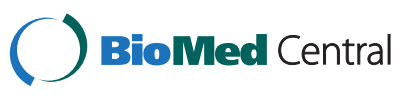

(c) 2012 Weber et al.; licensee BioMed Central Ltd. This is an Open Access article distributed under the terms of the Creative Commons Attribution License (http://creativecommons.org/licenses/by/2.0), which permits unrestricted use, distribution, and reproduction in any medium, provided the original work is properly cited. 
The NR superfamily has proliferated and diverged to a striking degree in the nematode Caenorhabditis elegans: while the C. elegans genome boasts 284 predicted NRs, the human genome has only 48 and the Drosophila melanogaster genome only 21 [5-8]. Only 15-20 C. elegans NRs are clearly orthologous to NRs that are broadly conserved among animal phyla [8]. The remaining (approximately 265) C. elegans predicted NRs appear to have evolved from an HNF4 ancestor and do not have clear orthologs in non-nematodes or distantly-related nematodes, suggesting that these genes have proliferated within the nematode phylum $[5,9,10]$. Nematode species that are closely related to $C$. elegans display a similar expansion of the NR gene family. Caenorhabditis briggsae and Caenorhabditis remanei, two species that are separated from C. elegans by about 100 million years and are morphologically indistinguishable from $C$. elegans, contain 232 and 256 NR genes, respectively [11]. Furthermore, only about half of $C$. elegans NRs are conserved in both $C$. briggsae and $C$. remanei as three-way orthologs, while an additional $10 \%$ are present as two-way orthologs [12]. Thus, the rapid expansion of the NR family appears to have begun before the separation of $C$. elegans, C. briggsae and C. remanei, and continued separately in all three species. The more distantly related nematode Pristionchus pacificus also has an expanded complement of 167 nuclear receptors [13,14], (R. Sommer, personal communication). The driving evolutionary explanation for this proliferation is unclear, but it could reflect adaptation to the complex chemical and xenobiotic environment of soil life [5-8]. In contrast, this expansion is not present in the genome of the nematode Brugia malayi, a human parasite: it contains only 27 NR genes, most of which are conserved across animal phyla [15]. Therefore, evolution of NRs is unexpectedly dynamic among free-living nematodes, suggesting that proliferation and divergence in the NR family may play a major role in nematode speciation. This possibility elevates the importance of understanding NR evolution and function in nematodes.

One explanation for the wide variety of Caenorhabditis NRs and the radiating divergence of LBD sequences is a lack of hormone-responsiveness. NRs that are known to bind ligands in other invertebrates, such as the ecdysone receptor, are absent in Caenorhabditis [5]. However, a bona fide ligand has been identified for the $C$. elegans NR DAF12 [16], and most C. elegans NRs have a recognizable LBD, raising the possibility that other $C$. elegans NRs may also bind as yet unknown ligands. Even if some Caenorhabditis NRs are not hormone-responsive, the LBD may be retained for its other functions, such as transcriptional modulation, receptor dimerization, and/or nuclear localization. In any of these cases, the wide variety of Caenorhabditis LBD sequences could reflect a wider diversity of inputs or outputs, or a relaxation of selection on LBD primary sequences.

The nuclear receptors have been grouped into phylogenetically conserved families on the basis of amino acid sequence relationship [7,17]. Members of the NR2E group include tailless (tll) and unfulfilled (unf) in Drosophila, Tlx and PNR in vertebrates, and nhr-67 and fax-1 in $C$. elegans. These NRs have been systematically defined as NR2E1 through NR2E5. Another family member, designated NR2E6, has been identified in insects [18]. The NR2E nuclear receptors that have been functionally characterized have a common theme of function in nervous system development. While mutations in the $t l l$ gene of Drosophila were first identified based on their disruption of anterior-posterior patterning, subsequent analysis demonstrated functions in embryonic CNS and larval eye development $[19,20]$. The mouse $T l x$ gene functions in limbic system and eye development, but is not required for overall patterning of the embryo [21-23]. C. elegans fax-1, its vertebrate homolog PNR, and Drosophila homolog unf all play key roles in regulating neuron development [24-29]. The NR2E class is of particular importance from an evolutionary perspective as well; it includes members from the cnidaria to vertebrates, indicating that it is of ancient evolutionary ancestry [4]. DNA-binding studies suggest that DBD properties of FAX-1 and NHR-67 are at least partially evolutionarily-conserved [30]. However, like other C. elegans LBDs, the NR2E class LBDs are more highlydiverged from each other and from orthologous LBDs.

We have studied the conserved NR2E class of NRs in C. elegans to examine how the low level of LBD sequence conservation affects function using an in vivo functional assay. Our analysis of C. elegans NR2E-related sequences identified one unstudied "satellite" nuclear receptor, $n h r-111$, which is related to fax-1, but is not present in any other genome sequenced to date, and another NR, $n h r-239$, which is a member of new, relatively uncharacterized clade of conserved NRs found in nonvertebrate animals that includes insect $H r 83$. Using an in vivo functional assay, we tested whether LBD function was required for $f a x-1$ and if LBD functions of other NR2E genes could be substituted for the fax-1 LBD function.

\section{Results}

NR2E family receptors can be grouped into three major conserved clades

Systematic classifications of NRs have grouped vertebrate Tlx-like genes into an NR2E1 subgroup, insect TLL-like genes into an NR2E2 subgroup, vertebrate PNR-like genes into an NR2E3 subgroup, and C. elegans FAX-1 as an NR2E5 subgroup [17,31,32]. Additional genes were designated NR2E4 and NR2E6, but these appear to be 
absent from both nematodes and vertebrates and are not considered further in this analysis. NR2E1 and NR2E2 subfamily members have very similar DBDs and DNAbinding activities, as do NR2E3 and NR2E5 subfamily members [30,33,34]. Ecdysozoans have an NR2E2, but not an NR2E1, and vice versa for vertebrates. The simplest explanation for this relationship is the existence of a single common ancestral gene for NR2E1/NR2E2. A similar scenario is likely for the NR2E3/NR2E5 group.

The C. elegans genome project identified the NR2Elike nuclear receptor $n h r-239$ after the publication of a broad phylogenetic analysis to resolve evolution of the NR superfamily [32]. In order to determine the phylogenetic relationship of $n h r-239$ to other nematode and non-nematode nuclear receptors, we performed Clustal W multiple sequence alignment and constructed trees using Maximum Likelihood and Neighbor-Joining methods with the predicted C. elegans NHR-239 protein sequence. In addition to trees based on aligned DBD and LBD sequences (Figure 1), we also evaluated trees using the DBD alone, since substitution rates in Caenorhabditis LBDs are much higher than in other species, which would lead to artificially inflated branch lengths for fulllength Caenorhabditis NRs. We included nuclear receptors from complete or nearly complete genome projects, including ecdysozoans (C. elegans, C. briggsae, Pristionchus pacificus, Brugia malayi, Aedes aegypti, Anopheles gambiae, Drosophila melanogaster, and Tribolium castaneum), vertebrates (Homo sapiens, Mus musculus, Gallus gallus, Xenopus laevis, and Danio rerio), a hemichordate (Saccoglossus kowalevskii), an echinoderm (Strongylocentrotus purpuratus), and a cnidarian (Nematostella vectensis). Maximum Likelihood and NeighborJoining computational methods produced similar results. C. elegans NHR-239 was organized into a diverged NR2E-like clade that includes relatively unstudied nuclear receptors from invertebrates, including the Drosophila nuclear receptor Hr83 (Figure 1). Because this group includes genes from deuterostomes (Saccoglossus and Strongylocentrotus), we infer that the NHR239/Hr83 clade derives from a gene that was present in the urbilaterian ancestor, but has subsequently been lost from vertebrate lineages.

Phylogenetic trees with full-length NR2E sequences also identified a highly-supported PNR/FAX-1 clade, with ecdysozoan clade members on one branch and deuterostome clade members on a separate branch (Figure 1). As observed in earlier phylogenetics analyses [32], a single TLX/TLL clade was not supported, with ecdysozoan, hemichordate, and vertebrate clade members occupying separate unresolved branches. Analysis of the DBD alone, however, organized vertebrate TLX and ecdysozoan TLL members into a single clade (Additional file 1: Figure S1). The C. elegans FAX-1 DBD very closely resembled those of
D. melanogaster UNF (92.9\% identical) and H. sapiens PNR (83.3\% identical), but it was much less similar to the D. melanogaster Hr83 DBD (64.3\% identical; Table 1; Additional file 1: Figure S1). In contrast, the C. elegans NHR239 DBD was more similar to D. melanogaster Hr83 than to DmUNF (60.7\% vs. $57.1 \%)$. Taken together, we interpret these data to define three major conserved clades of NR2E NRs: a TLX/TLL clade, a PNR/FAX-1 clade, and an NHR239/Hr83 clade.

Previous analysis and annotation of NR2E NRs did not benefit from complete data sets and were not focused on the NR2E group in particular. Two phylogenetic analyses of NRs that did not include NHR-239 grouped C. elegans FAX-1 with Drosophila Hr83 [32,34]. These analyses were performed with phyletically-broad datasets using fulllength NRs. When C. elegans NRs are included, the relatively high divergence of the LBD tends to pull C. elegans branches out of clades, leading to the possibility for long-branch attraction to weakly assemble C. elegans NRs into clades to which they do not belong [37]. This has led to an annotation problem where some members of the NHR-239/Hr83 clade, including Hr83 itself, have been designated "Fax1" and received an NR2E5 systematic designation (Table 2). The inclusion of our larger set of NHR-239/Hr83 data argues that this annotation is misleading and should be revised.

Analysis of aligned DBD sequences also revealed amino acids at certain positions that were diagnostic for each of three clades (Figure 2). Analysis of the PNR/FAX-1 clade identifies six amino acid positions in the DBD that are identical among all members of this clade, including Asn-19, which plays a key role in DNA-binding specificity [30], and Gln-38, which is predicted to mediate protein dimerization contacts [46]. The TLX/TLL and NHR-239/Hr83 clades have a conserved Asp-19, suggesting some possible overlap in DNA-binding specificity. The TLX/TLL group has seven clade-specific positions, including the potentially important Lys-38 [46]. All three nematode TLX/TLL clade members (NHR-67) have a D box that is expanded by an insertion of four amino acids (relative to most NRs) as compared to a single D box amino acid insertion for TLX and TLL proteins from non-nematodes (Figure 2). This suggests that dimerization properties of nematode NRs may have diverged from other clade members. Finally, the NHR239/Hr83 group has five clade-specific positions, including Ile-38 and Trp-57 (which is a statistically infrequent amino acid [47]), both of which are positions predicted to be involved in DNA-binding and dimerization (Figure 2). The coordinated conservation of these residues may reveal functionally-significant positions that help determine specificity, and supports the organization of these clades as representing distinct evolutionary origins.

As expected, the Caenorhabditis NR2E LBDs aligned more poorly than the DBDs with insect and vertebrate 


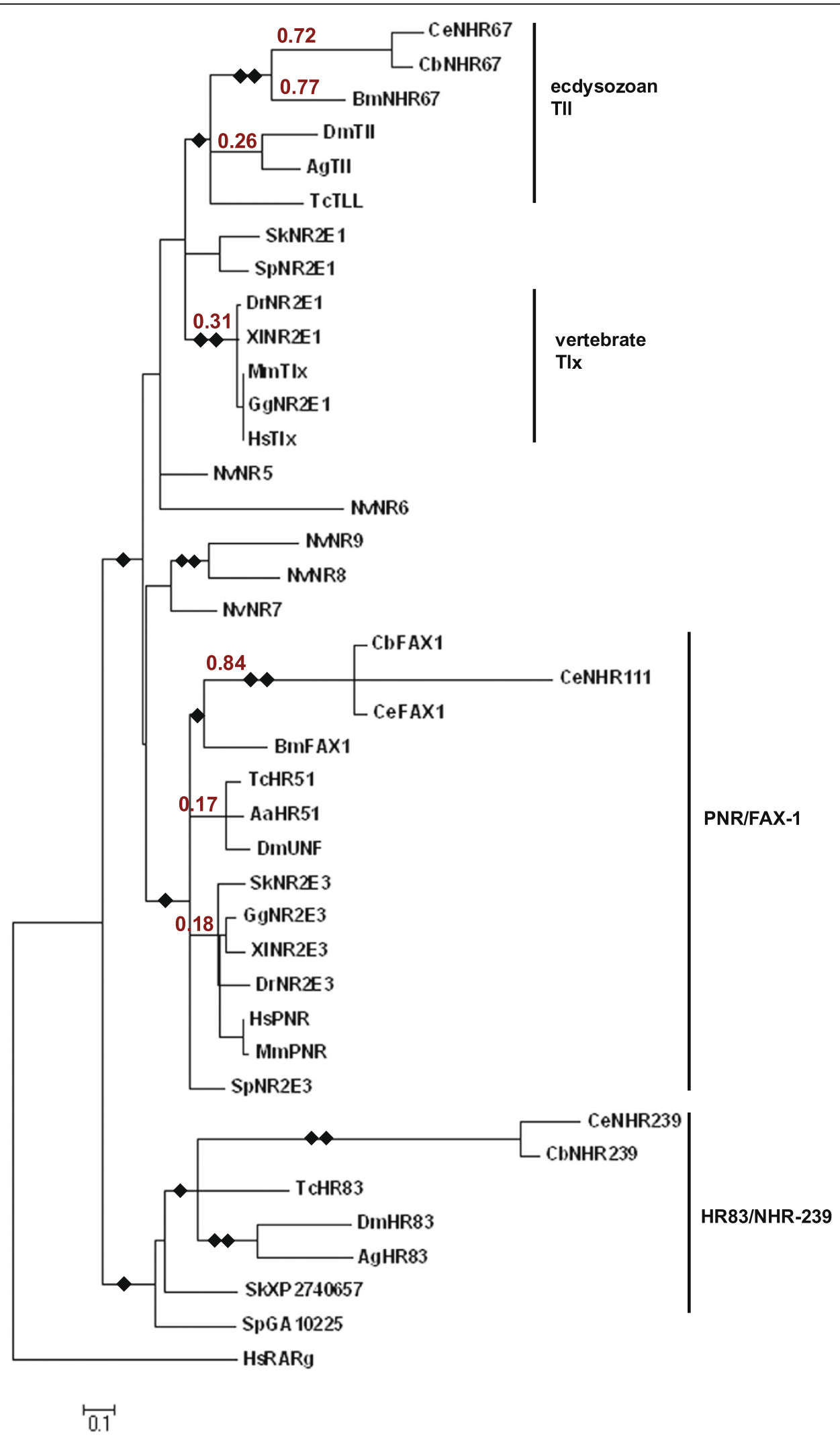


(See figure on previous page.)

Figure 1 Phylogenetic analysis of NR2E NRs. Maximum Likelihood trees of ClustalW-aligned amino acid sequences were calculated using MEGA $5.0[35,36]$. Highly-divergent regions N-terminal to the DBD and C-terminal to the LBD were not included. A consensus tree generated from 500 bootstrap replicates and rooted to the Homo sapiens retinoic acid receptor gamma outgroup sequence is shown. Further details are provided in Methods. Species abbreviations (used throughout): Ce (or no annotation):Caenorhabditis elegans, Cb: Caenorhabditis briggsae, Bm: Brugia malayi, Pp: Pristionchus pacificus, Dm: Drosophila melanogaster, Ag: Anopheles gambiae, Tc: Tribolium castaneum, Sk: Saccoglossus kowalevskii, Sp: Strongylocentrotus purpuratus, Dr: Danio rerio, Xl: Xenopus laevis, Mm: Mus musculus, Gg: Gallus gallus, Hs: Homo sapiens, Nv: Nematostella vectensis, Aa: Aedes aegypti. Tree is proportionally scaled, with the scale bar indicating sequence distance in units of substitutions. Single diamonds identify branchpoints that were supported by $>50 \%$ of bootstrap replicates; double diamonds identify branchpoints that were supported by $>95 \%$ of bootstrap replicates. Numbers in red above selected branches show Ka/Ks ratios for the LBD portion only of NRs.

orthologs (Table 1; Additional file 2: Figure S2). Ka/Ks ratios for LBD regions (Figure 1) at branches that lead to nematode NRs were high (0.72 to 0.84 ), in comparison

Table 1 Percent identities between NRs by domain

\begin{tabular}{|c|c|c|}
\hline & \multicolumn{2}{|c|}{$\%$ IDENTICAL } \\
\hline & DBD & LBD \\
\hline \multicolumn{3}{|c|}{ CeFAX-1 compared to: } \\
\hline CbFAX-1 & $100.0 \%$ & $69.0 \%$ \\
\hline BmFAX-1 & $94.0 \%$ & $17.2 \%$ \\
\hline PpFAX-1 & $93.0 \%$ & $10.4 \%$ \\
\hline DmUNF & $92.9 \%$ & $17.3 \%$ \\
\hline HsPNR & $83.3 \%$ & $16.4 \%$ \\
\hline CeNHR-67 & $65.5 \%$ & $12.7 \%$ \\
\hline HsTLX & $66.7 \%$ & $15.5 \%$ \\
\hline CeNHR-111 & $57.1 \%$ & $25.0 \%$ \\
\hline DmHR83 & $64.3 \%$ & $16.4 \%$ \\
\hline \multicolumn{3}{|c|}{ DmUNF compared to: } \\
\hline BmFAX-1 & $89.3 \%$ & $45.9 \%$ \\
\hline PpFAX-1 & $86.0 \%$ & $12.1 \%$ \\
\hline HsPNR & $83.3 \%$ & $50.8 \%$ \\
\hline \multicolumn{3}{|c|}{ CeNHR-67 compared to: } \\
\hline CbNHR-67 & $95.2 \%$ & $67.2 \%$ \\
\hline BmNHR-67 & $89.3 \%$ & $27.3 \%$ \\
\hline PpNHR-67 & $88.5 \%$ & N/A \\
\hline DmTLL & $84.5 \%$ & $18.5 \%$ \\
\hline HsTLX & $76.2 \%$ & $18.1 \%$ \\
\hline \multicolumn{3}{|c|}{ DmTLL compared to: } \\
\hline BmNHR-67 & $84.5 \%$ & $21.4 \%$ \\
\hline PpNHR-67 & $79.3 \%$ & N/A \\
\hline HsTLX & $82.1 \%$ & $42.9 \%$ \\
\hline \multicolumn{3}{|c|}{ CeNHR-239 compared to: } \\
\hline CbNHR-239 & $90.5 \%$ & $54.9 \%$ \\
\hline PpNHR-239 & $68.7 \%$ & N/A \\
\hline DmHR83 & $60.7 \%$ & $8.5 \%$ \\
\hline SkXP2740657 & $64.3 \%$ & $8.6 \%$ \\
\hline DmUNF & $57.1 \%$ & $8.5 \%$ \\
\hline
\end{tabular}

Amino acid sequences were aligned by ClustalW and evaluated using MEGA 5.0 software $[35,36]$. Figures shown are the percent identical at each amino acid position in pairwise comparison, with unaligned regions deleted. Species abbreviations are given in Figure 1. to branches that lead to insect or vertebrate NRs (0.17 to 0.31). In contrast, $\mathrm{Ka} / \mathrm{Ks}$ ratios for $\mathrm{DBD}$ regions (Additional file 1: Figure S1) were relatively low at nematode and non-nematode branches $(0.04$ to 0.21 for the more strongly-conserved PNR/FAX-1 and TLX/TLL clades). These data suggest strong purifying selection on the DBD across phyletic groups and very weak purifying selection on nematode LBDs. Furthermore, some key positions in the LBD signature domain and other regions that are conserved in insects and vertebrates have diverged in Caenorhabditis (Additional file 2: Figure S2). The Brugia malayi orthologs of FAX-1 and NHR-67 seem to have followed different evolutionary histories. While the LBD of Brugia FAX-1 looks similar to Drosophila UNF (45.9\% identical) and human PNR (50.8\%), the LBD of B. malayi NHR-67 looks more similar to C. elegans NHR-67 (27.3\% identical) than to $D$. melanogaster (21.4\%; Table 1). Therefore, the B. malayi FAX-1 LBD appears to have followed an insect-like path, while the B. malayi NHR-67 LBD appears to have followed a free-living nematode-like path. The NHR-239 /Hr83 clade LBDs are considerably more diverged from each other and the LBDs of other clades (Table 1; Additional file 2: Figure S2). This was particularly true for $C$. elegans and C. briggsae NHR-239, which align very poorly in the LBD signature region with other NR2E LBDs and are apparently truncated (Additional file 2: Figure S2). This observation suggests that Caenorhabditis NHR-239 may lack a bona fide LBD, like C. elegans ODR-7 and Drosophila KNIRPS [48,49].

Analysis of NR2E nuclear receptors of the nematode Pristionchus pacificus suggested extensive sequence divergence of LBDs in this species. While the predicted $P$. pacificus FAX-1 ortholog aligned well with PNR/FAX-1 clade DBDs (Figure 2; Table 1), the predicted LBD aligned very poorly (Table 1; Additional file 2: Figure S2). In particular, key features of the LBD signature domain that were present in other nematode LBDs were not found in the P. pacificus FAX-1 LBD. Analysis of P. pacificus genomic sequence also identified candidate NHR67 and NHR-239 orthologs by conservation of DBD sequences (Figure 2; Table 1), but failed to identify coding sequences or gene assembly models with similarity to TLX/TLL and NHR-239/Hr83 clade LBDs (data not 
Table 2 Annotation of NR2E orthologs by clade

\begin{tabular}{|c|c|c|c|}
\hline Human & C. elegans & Drosophila & Other species \\
\hline$T / X$ & $n h r-67$ & tailless & Nematostella NvR5 (2) \\
\hline \multirow[t]{8}{*}{ [NM 003269] } & [NM 069693] & [NM 079857] & -——-二-二- \\
\hline & & & Apis AmTII (3) \\
\hline & & & Bombyx TII (4) \\
\hline & & & Tribolium TII (5) \\
\hline & & & Brugia BmNHR-15 (6) \\
\hline & & & Schmidtea Tlx (7) \\
\hline & & & Strongylocentrotus TII (8) \\
\hline & & & Saccoglossus NP $001158362 ; \mathrm{TII}$ (9) \\
\hline$P N R$ & $f a x-1$ & unfulfilled/ & Nematostella NvR6-NvR9 (2) \\
\hline \multirow[t]{5}{*}{ [NM 016346] } & [NM 076146] & $\operatorname{Hr} 51$ & ーー一ーー————- \\
\hline & & [NM 137188] & Apis AmHr51 (3) \\
\hline & & & Bombyx BmHr51 (4) \\
\hline & & & Tribolium Hr51 (5) \\
\hline & & & Brugia BmNHR-16 (6) \\
\hline
\end{tabular}

Strongylocentrotus Pnr (8)

Saccoglossus NP 001158447; PNR (9)

No ortholog nhr-239 Hr83 (1) Nematostella NvR6-NvR9 (2)

[NM 065178] [NM 141390]

Apis AmHr83 (3)

Bombyx ortholog not identified (4)

Tribolium Hr83 (5)

Brugia BmNHR-C* (6)

Strongylocentrotus "Fax1" (8)

Saccoglossus XM 002740611; "NR6A1-like” (9)

(1) Annotated as Drosophila "Fax-1" in [32].

(2) Nematostella vectensis, four NR2E orthologs not clearly resolved, [38], this work.

(3) Apis mellifera [39].

(4) Bombyx mori [40].

(5) Tribolium castaneum $[18,41]$.

(6) Brugia malayi [15].

(7) Schmidtea mediterranea [42].

(8) Strongylocentrotus purpuratus [43].

(9) Saccoglossus kowalevskii [44,45], this work.

* Incomplete gene assembly, tentative gene designation. The "Other species" column is organized by taxonomic groups: cnidarian, ecdysozoa, echinoderm, and hemichordate.

shown). The $P$. pacificus genomic sequence is mostly complete [13], however gene assembly and confirmation by cDNA analysis is not yet comprehensive. Nonetheless, the absence of LBD sequences with a clear relationship to Caenorhabditis or Brugia NR2E LBDs suggests that LBD divergence of $P$. pacificus NR2E LBDs may be much greater than that observed in Caenorhabditis. This conclusion contrasts with the relatively strong conservation of LBD sequences reported for P. pacificus RXR (NR2B) and ecdysone (NR1H) receptors [50].

The C. elegans genome project also identified another potential NR2E gene family member, $n h r-111$. No clear 


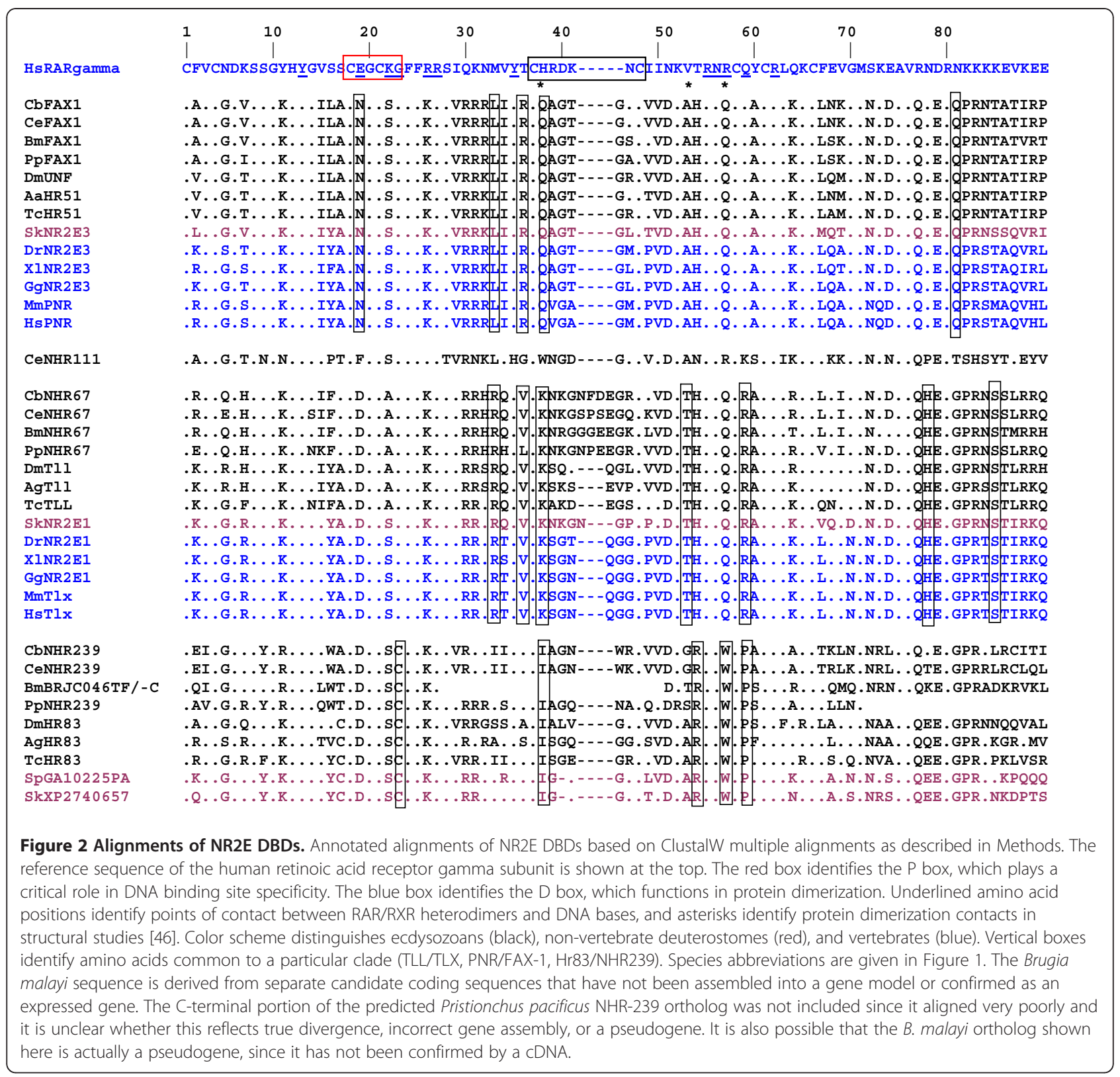

ortholog of $n h r-111$ has been identified in any other species, including the fully-sequenced and closely-related $C$. briggsae and $C$. brenneri nematodes. The NHR-111 sequence is included in the PNR/FAX-1 clade when fulllength proteins are considered (Figure 1), but is not included when the DBD alone is considered (Additional file 1: Figure S1). Alignment of the NHR-111 DBD revealed divergence of the NHR-111 DBD from other NR2E family members at multiple positions (Table 1; Figure 2). However, the NHR-111 DBD was still more similar to NR2E DBDs than to the DBDs of other nematode NRs (data not shown). Inclusion of NHR-111 in the full-length NR2E clade occurred due to extensive similarity between the NHR-111 LBD and FAX-1 LBD (25\% identical in Table 1; Additional file 2: Figure S2). From these observations, we propose that the $n h r-111$ gene arose from a relatively recent duplication of the $f a x-1$ gene in the $C$. elegans evolutionary lineage, followed by extensive divergence of the DBD.

The novel $n h r-111$ and $n h r-239$ NRs are expressed genes While fax-1 and $n h r-67$ have been studied in some detail, the $n h r-111$ and $n h r-239$ genes have not been characterized. Therefore, we considered the possibility that $n h r-111$ or $n h r-239$ could represent pseudogenes. While cDNA clones have been identified for $n h r-111$, spliced $n h r-239$ products have only been identified by deep sequencing (http://www.wormbase.org), suggesting 
that the latter transcript may be very rare. We used nested PCR to identify a partial $n h r-239$ cDNA from the 3 ' end of the gene, which confirms a portion of the predicted and deep-sequencing reported exon-intron structure (Figure 3A). We used real-time qRT-PCR to examine the temporal dynamics of $n h r-111$ and $n h r-239$ expression (Figure 3B). nhr-111 transcripts were detected at modest levels in embryos, but decreased progressively during larval development. nhr-239 transcripts were identified at very low levels (no more than $2 \times 10^{-6}$ the level of $18 \mathrm{~S}$ rRNA standards) and displayed a more complicated pattern, increasing somewhat from embryos to L1, before declining progressively during later larval development.

In order to examine cell-specific expression of both genes in living nematodes, we constructed $n h r-111:: g f p$ and $n h r-239:: g f p$ transgenes (Figure 3A). The $n h r-$ 111::gfp reporter was consistently expressed in at least eight pairs of neurons in the head, the sensory PVD neurons of the posterior lateral body wall, the pharynx, intestine (most often in the posterior- and anterior- most cells), the dorsal peri-vulva region of adults (which may be either uterine or vulval cells), and the somatic gonad precursor cells (Figure 3C). Among the head neurons was one prominent pair of sensory neurons just posterior to the nerve ring and at least one pair of neurons or support cells that appear to be inner or outer labial sensory cells. We also observed weak and variable expression in a subset of ventral nerve cord motorneurons. The temporal dynamics of $n h r-111:: g f p$ were consistent with $n h r-$ 111 qRT-PCR results: expression was very bright in the $\mathrm{Z1}$ and Z4 somatic gonad precursor cells in embryos and early L1, but decreased in the developing gonad at later stages and was relatively faint in other cells. Therefore, despite its relatively recent evolutionary origin, the $n h r-$ 111 gene is fairly broadly expressed.

The $n h r-239:: g f p$ reporter was weakly expressed in three to four pairs of neurons in the head and a pharyngeal neuron in late stage embryos and all larval and adult stages (Figure 3D). One pair of dorsal neurons express $n h r-239:: g f p$ very consistently and appear to be sensory, as do one pair of pharyngeal cells that appear to be the MC, NSM or M3 neurons. We observed faint fluorescence in the pharynx (which may be an artefact), but did not observe $n h r-239$ expression in other cells at any stage. As expected from the modest expression levels observed in qRT-PCR experiments, fluorescence from the $n h r-239:: g f p$ transgene was very faint. While it is possible that our translational fusion did not recapitulate the entire $n h r-239$ expression pattern, this result suggests that $n h r-$ 239 is expressed only in a very limited subset of neurons. Taken together, these data demonstrate that both genes are expressed, and that both may play roles in neuron development like other NR2E family members.

\section{FAX-1, NHR-67, and NHR-111 have predicted LBD} structures that are similar to defined vertebrate LBDs Like most C. elegans NRs, FAX-1, NHR-67, and NHR-111 proteins have extended $\mathrm{C}$-terminal regions after the $\mathrm{DBD}$ that have some features of canonical NR LBDs (Additional file 2: Figure S2). However, the greater divergence at the level of primary sequence makes diagnosis of a probable LBD more difficult in C. elegans than in Drosophila and other animals. In the case of NHR-239, the C-terminal region is truncated and much more highly diverged in both C. elegans and C. briggsae, suggesting that this NR has dispensed with a bona fide LBD. Lipophilic ligands generally bind internally to LBDs, raising the possibility that for NR LBDs, structure may be a more important consideration than primary sequence [51]. To examine the structural capacity for $C$. elegans NR2E C-terminal regions to encode LBDs, we used PSIPRED and the threading utility pGenTHREADER. This application compares predicted secondary structures derived from primary protein sequence to a database of solved tertiary structures to predict likelihood of structural match [52,53]. The $C$. elegans FAX-1, C. briggsae FAX-1, and C. elegans NHR-111 and NHR-67 LBDs all returned top matches to known vertebrate NR2 LBDs, with varying degrees of confidence (Table 3 ). The FAX-1 LBD was most similar to the NR2F2 COUP LBD, albeit with modest significance. The related NHR-111 LBD also matched NR2F2, with much higher significance. The NHR-67 LBD returned a very significant match to the NR2C2 testicular receptor 4 (TR4). In contrast, the NHR239 sequences did not return significant matches to any structures in the database. Therefore, despite relatively weak sequence conservation between Caenorhabditis LBDs and vertebrate LBDs, most NR2E Caenorhabditis LBDs retain a predicted structural framework that is similar to defined LBDs.

\section{The C. elegans FAX-1 LBD is not required for some functions in vivo}

The higher substitution rate of Caenorhabditis LBDs raised the possibility that nematode LBDs have broadly diverse functions-that diversifying selection has led to the evolution of highly-specific LBDs. In order to test this possibility, we used well-characterized fax 1 mutants and rescuing plasmids to serve as a basis for testing the functional requirements of the FAX-1 LBD [24,26]. A null mutation in the $f a x-1$ gene causes a distinctive movement defect. $C$. elegans normally moves with a smooth sine wave, but fax1 mutants are unable to generate coordinated muscle contractions in their posterior half, leading to severely compromised forward movement. Backing movement is more rapid, but inevitably leads to "coiling"-animals back into a circle on themselves instead of progressing straight backward. These defects may be due to underlying defects in the differentiation of the command interneurons that co- 


\section{A}

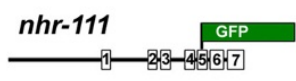

nhr-239

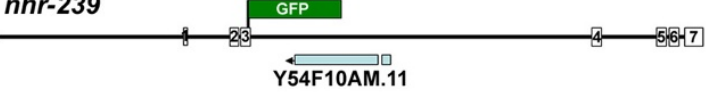

$\longmapsto 1 \mathrm{~kb}$

B

Expression of $n h r-111$ and $n h r-239$

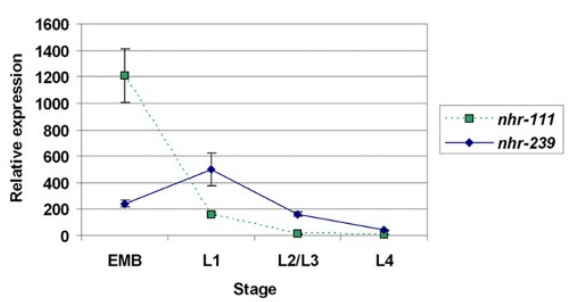

C
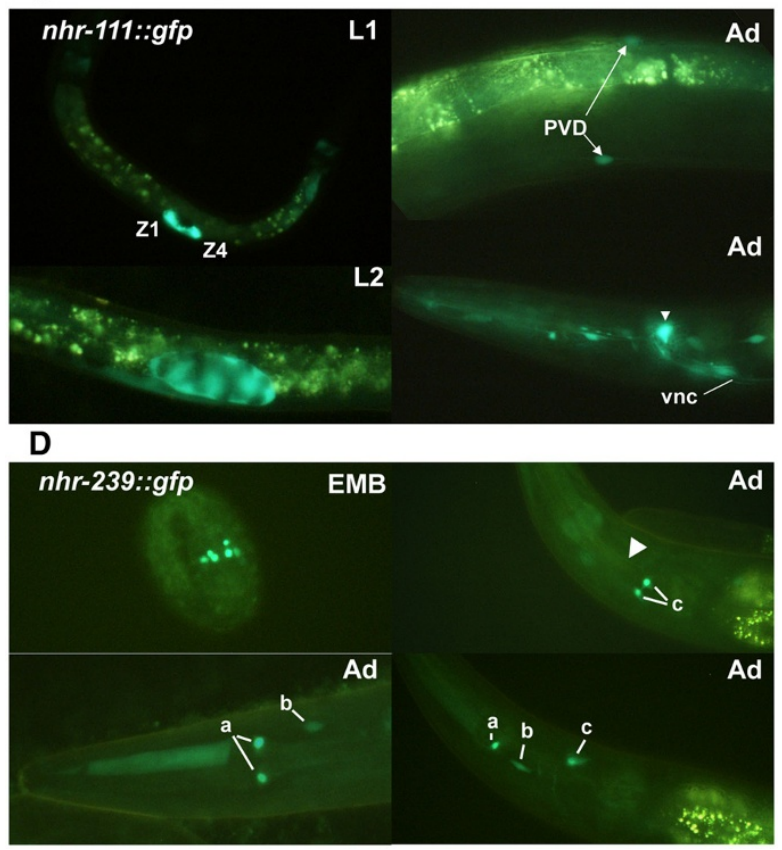

Figure 3 C. elegans $n h r-111$ and $n h r-239$ are expressed genes. The $n h r-111$ and $n h r-239$ genes and their expression patterns are shown. A. Schematic of the $n h r-111$ and $n h r-239$ genes showing the basic gene structure and point of fusion to GFP in expression constructs. B. Expression of the $n h r-111$ and $n h r-239$ genes over time as measured in qRT-PCR experiments. Arbitrary expression units are $2^{-\Delta C t} \times 10^{10}$. Error bars represent the standard deviation among replicates. Data from embryos (EMB) and larval L1, L2/L3, and L4 preparations of wild-type CDNA are shown. C. Expression of the nhr-111::gfp transgene in L1, L2 and adult (Ad) animals. The Z1 and Z4 gonad precursors in the L1 are labelled. The L2 image shows expression throughout the developing somatic gonad. The PVD neurons and ventral nerve cord (vnc) are indicated in the adult panels. Arrowhead identifies the location of a prominent dorsal neuron that appears to be sensory. D. Expression of the nhr-239::gfp transgene in a twofold embryo (EMB) and adult (Ad) hermaphrodites. Individual neuron pairs are identified by lower case letters: a, pair of pharyngeal neurons; $b$, pair of mid-lateral neurons or neuronal support cells; $c$, pair of dorsal neurons just posterior to the nerve ring with sensory dendritic processes (arrowhead). Due to the low level of nhr-239::gfp expression, brightness of the images in D was significantly increased relative to those in C. 
Table 3 Structural predictions for Caenorhabditis LBDs by sequence threading

\begin{tabular}{llll}
\hline LBD & Best structural match & PDB ID & P \\
\hline CbNHR-67 & H. sapiens NR2C2 TR4 LBD & $3 \mathrm{pOu}$ & $1 \times 10^{-6}$ \\
\hline CeNHR-67 & H. sapiens NR2C2 TR4 LBD & $3 \mathrm{p} 0 \mathrm{u}$ & $9 \times 10^{-7}$ \\
\hline CbFAX-1 & H. sapiens NR2F2 COUP LBD & $3 \mathrm{cjw}$ & 0.024 \\
\hline CeFAX-1 & H. sapiens NR2F2 COUP LBD & $3 \mathrm{cjw}$ & 0.003 \\
\hline CeNHR-111 & H. sapiens NR2F2 COUP LBD & $3 \mathrm{cjw}$ & $1 \times 10^{-5}$ \\
\hline CbNHR-239 & No significant matches. & - & $>0.10$ \\
\hline CeNHR-239 & No significant matches. & - & $>0.05$
\end{tabular}

Probability values (P) and top match for Caenorhabditis LBDs based on PsiPred and pGenThreader [52,53]. Additional significant matches to known NR LBD structures were obtained for each protein, however the significance of matches for both FAX-1 LBDs was low. Species abbreviations are given in Figure 1.

ordinate forward and backward motility [26,54]. fax-1 mutations affect multiple interneuron types. In the AVK interneuron pair, $f a x-1$ mutations cause a high-penetrance defect in axon pathfinding: instead of the AVKR and AVKL axons extending on the respective left and right sides of the ventral nerve cord, the axons are misrouted to the dorsal nerve cord, a lateral nerve bundle, or extend as a pair along the right ventral nerve cord [24]. The anatomy of the AVK neurons can be easily evaluated using antiFMRFamide antisera [55,56]. fax-1 function in AVK development is presumably a separate function from the $f a x-1$ function in movement, since the AVK neurons are not known to be required for movement coordination.

To test LBD function, we created a family of DNA constructs that would produce fusion proteins that contained the FAX-1 DBD fused to another NR2E LBD, and a protein that would contain only the FAX-1 DBD without any LBD. Plasmids were based on a $9 \mathrm{~kb}$ genomic fragment that fully-rescued the fax-1 movement and AVK axon phenotypes [24]. For each construct, the genomic region between exon 4 and exon 7 was replaced by a cDNA containing a positive control $f a x-1$ cDNA sequence (FAX$1::$ FAX-1), a negative control fax-1 cDNA sequence in inverted orientation (FAX-1::INV FAX-1), a deleted version of the $f a x-1$ LBD (FAX-1:: $\triangle \mathrm{LBD}$ ) or a cDNA sequence from the C. briggsae fax-1, nhr-111, or nhr-67 LBD (FAX-1::CbFAX-1, FAX-1::NHR-111, or FAX-1::NHR-67; Figure 4A). This strategy created plasmids that would produce FAX-1 DBD::heterologous LBD translational fusion proteins in which the region coding for the FAX-1 DBD was linked to an LBD-coding segment that began in the "hinge region" that separates DBD and LBD, and which replaced the FAX-1 LBD. The encoded fusion genes and deletion construct were under the transcriptional regulation of the $f a x-1$ promoter in order to ensure expression of the fusion or deleted protein at the correct time and in the correct cells for $f a x-1$ function.
In order to test the ability of the fusion and deletion constructs to provide in vivo fax-1 function, we injected each plasmid into fax-1(gm83) lin-15(n765ts) C. elegans hermaphrodites, along with a co-transforming plasmid that provides wild-type lin-15 function. For each transgenic line, we evaluated $f a x-1$ function by measuring forward movement rates (Figure 4B). While wild-type worms had a forward movement rate of $19.4( \pm 5.6, \mathrm{~N}=10) \mu \mathrm{m} / \mathrm{sec}$, fax -1 (gm83) mutants, fax-1(gm83) mutants transformed with the lin-15- rescuing plasmid alone, and $f a x-1$ (gm83) mutants transformed with the FAX-1::INV FAX-1 negative control had forward movement rates of 2.40 (s.d. 1.6, $\mathrm{N}=10$ ), 2.34 (s.d. $1.5, \mathrm{~N}=10$ ), and 1.23 (s.d. $1.3, \mathrm{~N}=10) \mu \mathrm{m} / \mathrm{sec}$, respectively (differences among speeds for negative controls were not statistically significant). The FAX-1::FAX-1 positive control provided a significantly rescued $(\mathrm{p}<0.00001)$ forward movement of 9.6 (s.d. $4.2, \mathrm{~N}=14) \mu \mathrm{m} / \mathrm{sec}$. When the $f a x-1$ DBD region was fused to another Caenorhabditis LBD, we obtained significant rescue $(\mathrm{p}<0.00001)$ of the $f a x-1$ movement phenotype: forward movement rates ranged from 9.33 (s.d. 3.4, $\mathrm{N}=10) \mu \mathrm{m} / \mathrm{sec}$ (for FAX-1::NHR-111) to 13.7 (s.d. 4.0, $\mathrm{N}=10) \mu \mathrm{m} / \mathrm{sec}$ (for FAX-1::NHR-67). Likewise, the FAX-1:: $\triangle$ LBD construct, which contains no LBD at all, was able to provide a robust forward movement rate of 14.7 (s.d. 6.2, $\mathrm{N}=17$ ) $\mu \mathrm{m} / \mathrm{sec}$. Differences between C. elegans FAX-1, C. briggsae FAX-1, and NHR-111 fusion pairs were not statistically significant $(\mathrm{p}>0.5)$, but the increased rescue with the NHR-67 LBD or $\triangle$ LBD constructs as compared to other LBDs was significant ( $\mathrm{p}=0.008$ to 0.05 ). The reason for the improved rescue by the NHR-67 LBD and $\Delta$ LBD constructs is not clear. It may reflect a larger number of copies in the transgene, array-specific variation in transcription levels, or structural differences at the level of protein fusion. Therefore, despite a conserved LBD structure and ligand-binding signature region, the FAX-1 LBD is not required for $f a x-1$ function in the development of neurons that control movement.

We also examined rescue of the $f a x-1$ phenotype at the level of AVK axonal anatomy $[24,56]$ by the heterologous and deletion LBD constructs. Negative controls displayed a high rate of AVK pathfinding defects in which the AVKR axon was absent from the right ventral nerve cord bundle, while transgenic animals bearing LBD fusions displayed rescue of the AVK pathfinding defect consistent with rescue of the movement defect (Figure 4C; Table 4). In the lin-15(n765ts) background, $97 \%$ of $f a x-1$ (gm83) displayed the AVKR axonal defect, an increase from the $78 \%$ of $f a x-1(g m 83)$ mutants that showed this defect. lin-15 functions in vulval development, and this enhancement may reflect the role of vulval precursor cells in organizing the normal bundling arrangement of the ventral nerve cord [57]. The presence of ectopic developing vulvae along the ventral mid-line of lin-15 mutant animals may increase the severity of the AVKR 


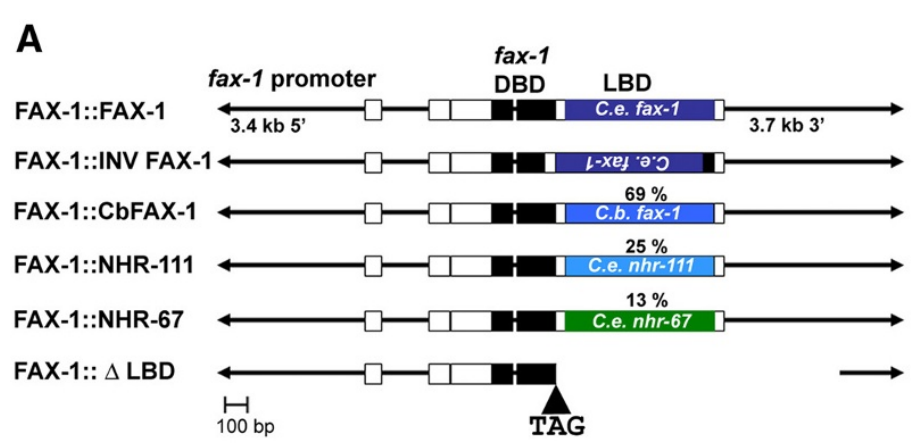

B
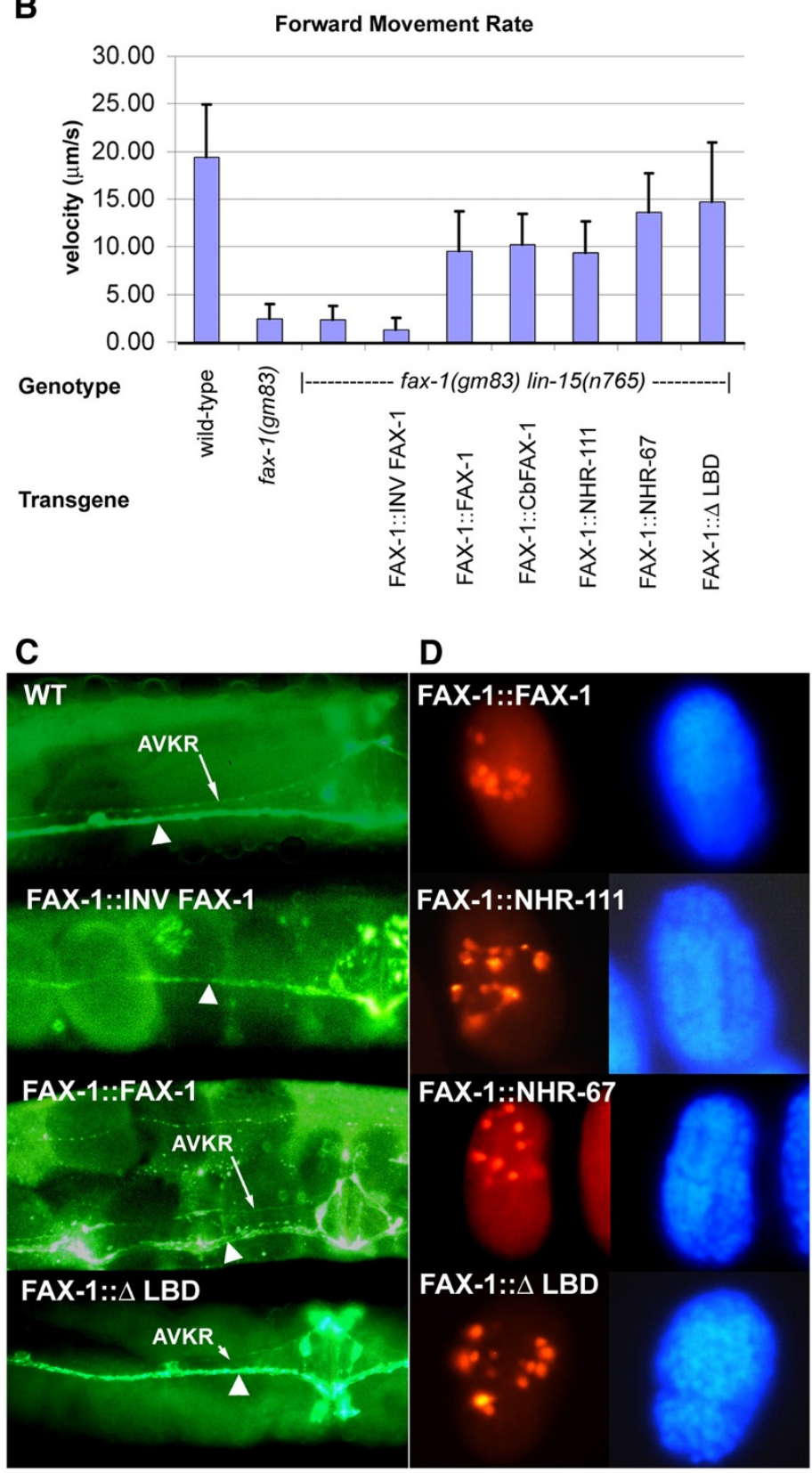
(See figure on previous page.)

Figure 4 Evaluation of LBD function for FAX-1. Design and results of the experiments with LBD swaps among different NR2E LBDs and a deletion of the FAX-1 LBD. A. Schematic showing design of the genomic constructs created to test LBD function, as described in Methods. Percentages above LBD boxes indicate the percent identity of the swapped LBD to the C. elegans FAX-1 LBD. B. Results of movement assays. Figure shows forward movement rates for control wild-type, fax-1(gm83), fax-1(gm83) lin-15(n765) and FAX-1:INV FAX-1 strains, as well as each swap construct transgene. C. Rescue of the AVKR pathfinding defect in fax-1 (gm83) mutants by LBD swap transgenes. The wild-type hermaphrodite shows a prominent single AVKR axon located in its proper position in the left bundle of the ventral nerve cord [56]. In the FAX-1:: INV FAX-1 negative control, the AVKR axon is missing from the ventral nerve cord due to misrouting [24]. The FAX-1::FAX-1 and FAX-1:: $\Delta$ LBD transgenic animals show the rescued wild-type anatomy. Rescue by FAX-1::Cb FAX-1, FAX-1::NHR-111, and FAX-1::NHR-67 transgenes was equivalent to the examples shown. The circular circuitry of FMRFamide-positive axons around the vulva is at the right side of each figure. All views are ventral views. D. Immunofluorescence demonstrating expression of fusion and deletion transgenes in fax-1 (gm83) lin-15(n765) embryos. Left panels show Cy3 fluorescence detecting the FAX-1 DBD, right panels show matching DAPI staining of nuclei. The FAX-1::FAX-1 and FAX-1:: $\Delta$ LBD embryos are a somewhat earlier stage ("late comma"), as compared to the FAX-1::NHR-111 and FAX-1::NHR-67 embryos ("two-fold elongation"). The anterior side of each embryo is oriented toward the top. Because of movement of elongation-stage embryos within the egg, orientation of each embryos varies.

axonal defect by contributing post-outgrowth bundling defects during larval development. The FAX-1::INV FAX-1 negative control displayed no rescue of the AVKR axon defect, but LBD fusion constructs with $C$ elegans FAX-1, C. briggsae FAX-1, NHR-111, and NHR-67 all displayed significant rescue of the AVKR axon defect, reducing the penetrance of the defect to between 33\% and $61 \%$ (Figure. 4C; Table 4). As was the case for the movement defect, rescue with FAX-1::NHR-111 was not as strong as with other Caenorhabditis LBDs. Therefore, at the level of axonal anatomy, different Caenorhabditis LBDs and a deletion of the LBD were able to provide FAX-1 function.

We confirmed expression and subcellular localization of our fusion and deletion products by immunofluorescence staining. A mouse anti-FAX-1 antiserum raised to full-length FAX-1 protein detected a strong signal in fax1(gm83) lin-15(n765) embryos that carried a FAX-1 DBD-contained transgene (Figure 4D). Because $f a x-1$ (gm83) mutants produce no detectable FAX-1 protein [26], the protein detected by the antiserum must reflect expression of the FAX-1 DBD that is common to all fusion and deletion construct transgenes. We detected strong expression by all four fusion transgenes (FAX-1:: FAX-1, FAX-1::CbFAX-1, FAX-1::NHR-111, and FAX-1:: NHR-67) and the FAX-1:: $\triangle$ LBD transgene in a spatial and temporal pattern that was nearly identical to the FAX-1 expression pattern in wild-type embryos [26], indicating that our constructs produced stable protein at the correct time and place (Figure 4D; data not shown). The FAX-1:: $\triangle$ LBD, FAX-1::FAX-1, FAX-1::CbFAX-1 and FAX-1::NHR-67 constructs also showed excellent nuclear localization, suggesting that the LBD is not required for import of FAX-1 protein to the nucleus. The FAX-1:: NHR-111 construct was expressed at very high levels, but many embryos showed significant accumulation of protein in the cytoplasm (Figure 4D). It is unclear whether this reflects an artefact of high expression levels or a "dominant" effect of the NHR-111 LBD that inhibits nuclear localization of the FAX-1::NHR-111 fusion protein. Despite the nuclear localization issue, the FAX-1:: NHR-111 construct still provided functional rescue,

Table 4 Rescue of AVKR pathfinding defects

\begin{tabular}{|c|c|c|c|c|}
\hline TRANSGENE & GENOTYPE & $\%$ AVKR DEFECT & $\mathbf{N}$ & $p$ \\
\hline none & wild-type & 0 & 27 & \\
\hline none & fax-1 (gm83) & 78 & 32 & \\
\hline fax-1 $9 \mathrm{~kb}$ genomic DNA & fax-1 (gm83) & 12 & 25 & \\
\hline none & fax-1 (gm83) lin-15 (n765) & 97 & 35 & \\
\hline FAX-1::INV FAX-1 & fax-1 (gm83) lin-15 (n765) & 92 & 53 & 0.55 \\
\hline$\overline{F A X-1:: F A X-1 ~ L B D}$ & fax-1 (gm83) lin-15 (n765) & 33 & 52 & $<0.001$ \\
\hline FAX-1::CbFAX-1 LBD & fax-1 (gm83) lin-15 (n765) & 36 & 22 & $<0.001$ \\
\hline FAX-1::NHR-111 LBD & fax-1 (gm83) lin-15 (n765) & 61 & 95 & $<0.001$ \\
\hline FAX-1::NHR-67 LBD & fax-1 (gm83) lin-15 (n765) & 41 & 39 & $<0.001$ \\
\hline FAX-1:: LBD & fax-1 (gm83) lin-15 (n765) & 62 & 63 & $<0.001$ \\
\hline
\end{tabular}

The percentage of the AVKR axon crossover defect [56] is shown for each strain. $\mathrm{N}=$ number of AVKR axons examined. $\mathrm{p}=\mathrm{Chi}$ square $\mathrm{P}$ values relative to fax-1 (gm83) lin-15(n756) strain without any transgene. 
although it is possible that the somewhat weaker rescue by this construct may be accounted for by the compromised nuclear localization.

\section{Discussion}

Analysis of LBD function in the C. elegans NR2E subfamily demonstrates the functional independence of some $f a x-1$ functions on the presence or sequence of the LBD. The simplest interpretation of this result is that the key FAX-1 functions that we have assayed require only binding of the DBD moiety to its cognate recognition site. This is consistent with our previous finding that the FAX-1 DBD alone possesses both sequence specificity and homodimerization function [30]. Furthermore, the DBD also appears to possess sufficient transcription regulation activity to confer normal function. In addition, the DBD expressed in vivo without an LBD appears to be efficiently localized to the nucleus, indicating that the LBD is not required for efficient localization. Finally, the absence of a requirement for the FAX-1 LBD demonstrates that it is not liganddependent-at least for the functions we have tested. The LBD of the Drosophila ortholog of fax-1, UNF, has been shown to bind heme [58], although there is no known developmental or physiological requirement for hemebinding. If the FAX-1 LBD can also bind heme-related ligands, our results suggest that this binding is not essential for key FAX-1 functions in C. elegans.

The independence of $f a x-1$ functions from the presence or identity of an LBD suggests that the relatively high level of primary sequence divergence of Caenorhabditis LBDs may not reflect diversifying selective pressure toward highly specific functional roles. Instead, the relatively high sequence divergence may result from a release of positive selection on the primary sequence, with sequence differences reflecting drift. Nonetheless, protein sequence threading suggests that some general aspects of secondary and tertiary LBD structure may be maintained in Caenorhabditis. Changes in selective pressure on nematode LBDs may have allowed a greater degree of tolerance for substitution within the context of conserved structure.

Analysis of C. elegans LBDs and the Caenorhabditis genomes has cast doubt on the hypothesis that C. elegans NRs mediate transcription using the same components as vertebrate systems. For example, the LBD of several vertebrate nuclear receptors have been shown to bind a common set of coactivators and corepressors, which in turn mediate the effect of the nuclear receptor on transcription [59]. However, an AF2 domain, which is contained within the many vertebrate LBDs and responsible for interaction with p160 coactivators, is absent from most Caenorhabditis NRs, including the fax-1 and nhr-239 orthologs in this study, and most of the known vertebrate NR coactivator and corepressor genes were absent from a survey of predicted genes in C. elegans [9]. Therefore, significant differences between vertebrates and Caenorhabditis in the mechanisms of transcriptional control may account for the apparent differences in LBD function in $C$. elegans.

The lack of a requirement for LBD function for fax1rescue in our assay does not necessarily indicate that the FAX-1 LBD provides no function or that C. elegans NR2E proteins in general are ligand-independent. On the contrary, the structural conservation of the C. elegans LBDs (Table 3), weak purifying selection on LBD sequences (Figure 1), and the general absence of truncated LBDs among conserved NRs in the C. elegans genome (save perhaps $n h r-239$ ), combine to argue that LBDs have been retained because they provide function. It is possible that the FAX-1 LBD is required for subtle aspects of developmental control that are not revealed by our rescue assay. Alternatively, the developmental functions that we have tested could be entirely LBDindependent, but other functions are LBD-dependent. This might be the case if FAX-1 provides an unknown physiological, ecological, or behavioural function during larval and/or adult stages. A precedent for both liganddependent and ligand-independent functions exists for vertebrate steroid NRs [60]. It is worth noting that all the C. elegans NR2E genes in this study are expressed in larval and adult cells (Figure 3, [26,61], which certainly allows for later functions in addition to the major embryonic developmental functions.

Our preliminary analysis of expression of $n h r-111$ and $n h r-239$ reveals some commonalities among members of the NR2E family in Caenorhabditis. First, all NR2E family members are expressed in subsets of neurons. In the two best studied cases, fax-1 and $n h r-67$, they play important roles in neuron differentiation and specificity [26,61], functions that are also maintained in flies and vertebrates $[23,27,62]$. While we have not yet determined functions for $n h r-111$ and $n h r-239$, the expression of both genes in subsets of neurons at a time in embryogenesis when neuronal specification is occurring suggests that they may also function in neuronal development. Furthermore, a genomic study focusing on neuron-specific transcriptional complexes identified 15 candidate gene targets for NHR-111, including the well-studied neuronal developmental control genes $u n c-30$ and unc-86 [63]. In addition, both NHR-111 and NHR-67 were found to bind a common target promoter, suggesting that they may be co-ordinately involved in regulating overlapping neuron-specific genes. A second feature common to all Caenorhabditis NR2E genes, except for $n h r-239$, is that they are expressed in the somatic gonad: $f a x-1$ in the distal tip cells during larval gonadogenesis [24], $n h r-67$ in the larval ventral uterine cells, anchor cell, and linker cell of the male $[64,65]$ and $n h r-111$ in the $\mathrm{Z} 1$ and Z4 gonad precursors and their descendants. Of 
these, only $n h r-67$ has a clearly defined function in uterine development. Nonetheless, the nexus of NR2E expression in somatic gonadal tissues raises the possibility for combinatoric functions within the NR family. At the very least $n h r-111$ expression overlaps with $n h r-67$ expression in the ventral uterine lineages and anchor cell, and with $f a x-1$ expression in the distal tip cells. The identification of common targets for both NHR-67 and NHR-111 supports the notion that these transcription factors may have overlapping functions. Arda et al. [66] have identified metabolic gene regulatory networks that are highly-enriched with NRs, both as components of transcription factor networks that regulate genes involved in metabolism, homeostasis, and environmental response, and as targets of regulation by NRs and other transcription factors. Both NHR-67 and NHR-111 were components of modules implicated in coordinated regulation of metabolic genes, similar to what was found with neuron-specific target genes. NHR-111 was also implicated in six additional smaller regulatory complexes, consistent with the relatively broad expression pattern we describe here.

The C. elegans NR2E genes that have been studied most thoroughly play various roles in development. Deletion of $n h r-67$ results in early developmental arrest [65]. Loss of fax-1 causes significant movement and nervous system defects, but does not cause lethality [24]. Like $n h r-67, n h r-$ 111 is expressed fairly broadly, but its deletion does not cause lethality or obvious morphological phenotypes (KW, GMB, SC, and BW, unpublished observations). This observation raises the possibility that NHR-111 may partner with other transcription factors in a highly-redundant and overlapping manner to fine-tune gene regulation in many cells. The observation that NHR-111 is a major node in the C. elegans interactome map of predicted protein interactions, partnering with itself (suggesting possible homodimerization) and 53 other proteins [67], many of which are potential transcription factors, provides some support for this hypothesis.

Finally, our phylogenetic analysis using a larger set of NR2E sequences from many species argues for three significant evolutionarily-conserved clades: TLL/TLX, FAX1/PNR, and NHR-239/Hr83. Our data call into question the hypothesis that FAX-1 and PNR represent different genes in the urbilateralian ancestor followed by subsequent loss of PNR in nematodes and loss of FAX-1 in vertebrates [32]. Not only do our phylogenetic data support an orthologous evolutionary origin for FAX-1 and PNR, direct examination of DBD alignments identify consistent conserved loci within each clade, a situation that is less likely to exist due to convergent evolution. A more parsimonious interpretation is a single urbilateralian ancestor for both PNR and FAX-1. To date, we know of no genome that includes a PNR ortholog, a FAX-1 ortholog and an NHR-239/Hr83 ortholog. Instead most animal genomes boast a single PNR-like gene or a single FAX-1-like gene, with a single NHR-239/Hr83 clade member and a single TLL/TLX clade member. Our interpretations of the relationship of NR2E receptors call into question the utility of the systematic nomenclature system for NRs [17] when applied to divergent C. elegans receptors. In this case, a version of long-branch attraction or similar artefact has resulted in a confusing situation in which C. elegans FAX-1 and insect Hr83 both have been assigned NR2E 5 even though FAX-1 is clearly more similar to insect NR2E3 and C. elegans NHR-239 is more similar to Hr83. This change in the evolutionary assumptions of the NR2E subfamily does not change predictions of the original number of NRs as described by Bertrand et al., [32], since the "new" NHR-239/Hr83 clade effectively replaces the "lost" FAX-1 clade that results from fusing FAX-1 and PNR into a single clade. In this case, a larger data set was important for drawing the clearest evolutionary inferences. Therefore, complex evolutionary patterns in large gene families may benefit substantially from large-scale sequencing projects that examine closely-related species, such as the current 959 Nematode Genomes project (http://www.nematodes.org).

\section{Conclusions}

We define three conserved clades of NR2E receptors, only two of which are represented in vertebrates. This observation suggests that there were three ancestral NR2E genes in the urbilateria. Additional genes have spawned from descendants of these three ancestral genes, including $n h r-111$, which is a broadly-expressed paralog that appears to have arisen within the Caenorhabditis evolutionary lineage. LBD function is not required for at least some important developmental functions of one NR2E family member. This result suggests that the relatively high level of sequence divergence for Caenorhabditis LBDs reflects relaxed selection on the primary sequence, rather than highly diversifying positive selection.

\section{Methods}

\section{Phylogenetics and computational analysis}

We aligned protein sequences using the alignment utility of MEGA 5.0 [36]. Alignments were performed with the Clustal W algorithm [37] using a BLOSUM matrix, a pairwise gap penalty of 10 , with extension penalty 0.1 , and a multiple alignment gap penalty of 10 , with extension penalty 0.2 . We developed phylogenetic trees using the Maximum Likelihood method based on the Dayhoff matrix based model [47] and by Neighbor-Joining [68] using MEGA 5.0 software. All positions containing gaps were eliminated. The bootstrap consensus trees were inferred from 500 replicates. Trees were rooted manually to the Homo sapiens RAR gamma outgroup sequence. The trees were drawn to scale, with branch lengths measured in the 
number of substitutions per site. We evaluated LBD structures of NR2E proteins using PSIPRED and the threading utility pGenTHREADER $[52,53]$ at the Bloomsbury Centre for Bioinformatics at University College London [69]. We calculated $\mathrm{Ka} / \mathrm{Ks}$ ratios for DBD and LBD regions separately by generating matched Maximum Likelihood trees based on amino acid alignments and nucleotide alignments using Clustal W and MEGA 5.0 as described above. Not all sequences shown in Figure 1 and Additional file 1: Figure $\mathrm{S} 1$ were included in the $\mathrm{Ka} / \mathrm{Ks}$ analysis. Newick-formated trees were generated with MEGA 5.0 and edited by hand to create binary files. $\mathrm{Ka} / \mathrm{Ks}$ ratios were calculated using the $\mathrm{Ka} / \mathrm{Ks}$ utility at the Bergen Center for Computational Science, University of Bergen (http://www.bccs.uni.no/ units/cbu/).

\section{Nematode strains and GFP reporter analysis}

C. elegans were cultured as described by Brenner [70] and Stiernagle [71]. Strains were obtained from the Caenorhabditis Genetics Center, the National Bioresource Project of Japan, the C. elegans Gene Knockout Consortium. nhr-111::gfp and nhr-239::gfp constructs were created as illustrated in Figure 4. The nhr-111::gfp plasmid, pG3.9GFP1, was constructed by amplifying a $2.7 \mathrm{~kb}$ region from genomic cosmid clone F44G3 using oligonucleotides [Additional file 3: Table S1] and ligating the product to the GFP expression vector pPD95.79 using BamHI and SphI. The resulting plasmid fused the entire 5' flanking region of $n h r-111,1.2 \mathrm{~kb}$ from the predicted start codon to the predicted 3' end of the immediately adjacent upstream gene, and the genomic $n h r-$ 111 coding region into exon 5 to the coding sequence for GFP. The nhr-239::gfp plasmid, pNHR239GFP1, was constructed by amplifying a $2.8 \mathrm{~kb}$ region from wild-type C. elegans genomic DNA using oligonucleotides [Additional file 3: Table S1] and ligating the product to pPD95.79 using XbaI and XmaI. The resulting plasmid fused $2.1 \mathrm{~kb}$ of 5 ' flanking DNA, which includes the last intron and exon of the adjacent upstream feh-1 gene, and the first three predicted exons of the $n h r-239$ gene to the coding sequence for GFP. We introduced plasmid constructs into nematodes following standard microinjection techniques [72] using a Nikon UD Optiphot 2 microscope. Transgene-positive progeny were identified by the Roller phenotype conferred by the pRF4 cotransforming marker that bears a dominant mutant version of the rol-6 gene. We employed a Nikon Eclipse TE $2000 \mathrm{U}$ inverted microscope to examine nematodes using DIC Nomarski microscopy and captured images using a Nikon DMX 1200 camera. To examine and record GFP fluorescence patterns, we used a Nikon UD Optiphot 2 microscope and captured images using a Nikon DS camera. We cropped images and adjusted for optimum contrast and brightness using Adobe Photoshop software.

\section{Quantitative real-time qPCR}

We used quantitative real-time PCR (qRT-PCR) [73] to estimate relative levels of $n h r-111$ and $n h r-239$ expression. Taqman probe/primer mixtures were purchased from Applied Biosystems/Life Technologies (Carlsbad, CA). For both $n h r-111$ and $n h r-239$, manufacturerdesigned probes were used. In addition, we designed a confirmatory probe/primer mixture for $n h r-239$ using Applied Biosystems Primer Express 3.0 software. We prepared staged worm preparations for wild-type C. elegans nematodes as follows: embryos, treatment with $20 \%$ chlorine bleach and $0.1 \mathrm{M} \mathrm{NaOH}$; L1, bleach treatment followed by overnight incubation in M9 buffer; L2/L3, as for L1 followed by 24 hour feeding on OP50 bacteria at $20^{\circ} \mathrm{C}$; L4, as for L1 followed by 48 hour feeding on OP50 bacteria at $20^{\circ} \mathrm{C}$. Samples were washed in M9 exhaustively and frozen in RNALater solution (Ambion, Austin, TX). Total RNA was prepared using a RiboPure Yeast RNA kit (Ambion) as directed by the manufacturer. We synthesized cDNA using a High-Capacity cDNA Reverse Transcription Kit (Applied Biosystems) as directed by the manufacturer. Real-time qRT-PCR was conducted on a StepOnePlus system (Applied Biosystems) using Fast Taqman Master Mix (Applied Biosystems). All samples were tested in triplicate or quadruplicate. We measured expression levels in arbitrary units calculated as $2^{-}$ ${ }^{\Delta \mathrm{Ct}} \times 10^{10}$ relative to $18 \mathrm{~S}$ rRNA controls (18 S Eukaryotic Taqman Probe/Primer mix, Applied Biosystems).

\section{LBD swap and deletion experiments}

Plasmid pFXCDSp. 8 was constructed by cloning an 809 bp SphI fragment from a pFXCD5 fax-1 cDNA clone into vector pUC18, creating a basic fax-1 cDNA backbone clone for the purpose of replacing the fax-1 LBD coding region with cDNA for LBD coding regions of other NRs. To produce FAX-1::FAX-1 and FAX-1::INV FAX-1 constructs, we ligated the $809 \mathrm{bp}$ SphI fragment from pFXCDSp. 8 into genomic clone pF56SH9 [24] digested with SphI, thereby replacing the $f a x-1$ genomic region with a fax-1 cDNA in the correct (FAX-1::FAX-1) or inverted (FAX-1::INV FAX-1) orientation. To produce FAX-1:: $\triangle \mathrm{LBD}$, we digested the parent rescuing plasmid pF56SH9 with EcoNI and EagI (which deletes the entire LBD and a portion of the DBD), following by amplification of the 3' coding portion of the fax-1 DBD from a fax-1 cDNA clone using EcoNI and EagI- tailed oligonucleotides (Additional file 3: Table S1) and reconstitution of the intact DBD by ligation of the amplification product into the deleted pF56SH9 plasmid. In addition to a deletion of the LBD, this construct also deleted 468 bp of 3' UTR and flanking DNA. The resulting FAX-1:: $\triangle$ LBD plasmid construct was sequenced across the amplified region to 
confirm wild-type sequence and deletion of the LBD coding region. The LBD swap constructs were created by amplifying the corresponding LBD coding regions from $C$. briggsae fax-1, nhr-67, and nhr-111, using corresponding cDNA clones as template, and ligating each to vector pGEM-T Easy using oligonucleotides tailed with BclI, BamHI and/or EcoRI recognition sites (Additional file 3: Table S1). Each LBD cDNA construct was sequenced on both strands to confirm wild-type sequence. We created cDNA fusions for each swap construct by excising the target LBD cDNA with either BcII and EcoRI or BamHI and EcoRI, and ligating the fragment to BamHI/EcoRI-digested pFXCDSp.8. The resulting family of clones created FAX-1::swap LBD cDNA fusion clones with flanking SphI sites. Each cDNA fusion clone was digested with SphI and ligated to the SphI-digested fax1 genomic pF56SH9 clone in the proper orientation to create a family of genomic clones that contained replaced LBD cDNA regions. We used a lin-15 marker for transformation experiments since the more commonly-used Rol-6 marker would interfere with subsequent movement assays. Each plasmid construct (at $50 \mu \mathrm{g} / \mathrm{ml}$ ) and the lin-15-rescuing marker plasmid pSK1 (at $50 \mu \mathrm{g} / \mathrm{ml}$ ), was microinjected into fax-1(gm83) lin-15(n765ts) hermaphrodites that had been grown at $15^{\circ} \mathrm{C}$. The lin-15 mutation results in a multi-vulva (Muv) phenotype at the non-permissive temperature of $25^{\circ} \mathrm{C}$, but is near wild-type when grown at $15^{\circ} \mathrm{C}$. Injected hermaphrodites were grown at $25^{\circ} \mathrm{C}$ to allow identification of transformed non-Muv animals in the next generation. Each transgene was maintained as one or more independent extrachromosomal arrays by picking wild-type animals at $25^{\circ} \mathrm{C}$. For each construct we obtained at least two dozen transient F1 non-Muv transformants and established between two and twenty independent stable lines. Transgenic lines and control strains were evaluated for movement using a Nikon SMZ800 stereo dissection microscope outfitted with a Hitachi CCD camera KP-D20BU. Video was captured for 30 seconds per trial using Mitotic Images Plus software. Worm movement was measured by digital calibration of distance moved per second during bursts of forward movement. Some $f a x-1(g m 83)$ and non-rescued transgenic strains made no forward progress during the trial period, which was scored as $0 \mu \mathrm{m}$ of movement over the period of apparent attempted movement. We calculated forward movement speeds as $\mu \mathrm{m} / \mathrm{sec}$. The AVKR axon pathfinding phenotype of transgenic and control strains was evaluated using immunofluorescence and an anti-FMRFamide antibody as described previously $[24,56]$. We evaluated expression of deleted and fusion proteins from each transgene using immunofluorescence and a mouse anti-FAX-1 polyclonal antibody, and a Cy3-labeled Goat anti-mouse IgG secondary antibody as described previously [26]. The anti-FAX-1 antibody was raised to fulllength FAX-1 protein and was able to detect transgeneexpressed protein from each fusion construct and the deletion, indicating that the antiserum contains antibodies that recognize the DBD. Different transgenic lines containing the same construct differed somewhat in the rate at which the array transgene was transmitted, but did not differ substantially from each other in rescue or expression experiments. For each construct, the data reported here are from one representative transgenic strain.

\section{Additional files}

Additional file 1: Figure S1. Phylogenetic analysis of NR2E DBDS.

Additional file 2: Figure S2. Sequence alignments of NR2E LBDs.

Additional file 3: Table S1. Oligonucleotide sequences.

\section{Competing interests}

The authors declare that they have no competing interests.

\section{Authors' contributions}

KPW constructed the majority of the LBD fusion constructs, evaluated $n$ hr$111::$ gfp expression, performed some of the computational analysis, and edited the manuscript. CGA created and evaluated the nhr-239::gfp constructs, performed some of the GRT-PCR analysis, and edited the manuscript. GMB evaluated nhr-239::gfp expression and the $n h r-111$ mutations. KR created the nhr-111::gfp construct. GC contributed to construction of the LBD fusion constructs. SC performed genetic backcrossing, contributed to the LBD fusion constructs, managed some of the experiments, and edited the manuscript. BW conceived the project, drafted the manuscript, performed phylogenetics analysis, constructed the LBD deletion construct, performed the nematode transformations, some of the GFP expression analysis, and some of the qRT-PCR experiments. All authors read and approved the final manuscript.

\section{Acknowledgements}

Jennifer Baldwin, Dan Shpilksy, Jessica Tanis, and Matt Stein made early contributions to some of the data or constructs in this study. Marten Edwards, Amy Hark, Elizabeth McCain, and Jeremy Teissere of the Muhlenberg College Biology Department generously shared equipment, reagents and resources. Scott Clark provided pSK1 plasmid. We appreciate helpful discussions about this project with Ann Sluder, Chris Gissendanner, Piali Sengupta, and Marc Van Gilst. The anonymous reviewers provided critical and much-appreciated feedback. Wormbase, Wormatlas, and the Caenorhabditis Genetics Center provided critical resources for this work. Robert Barstead, Shohei Mitani, the National Bioresource Project, and the C. elegans Gene Knockout Consortium produced the knockout strain referred to in this study. KPW, KR, and GMB received funding from National Science Foundation Research Experiences for Undergraduates (REU) awards. This project was supported by Research at Undergraduate Institution (RUI) grants 0234716, 0640483, and 0948367 from the National Science Foundation to BW. The GRT-PCR experiments were performed using equipment purchased under Course, Curriculum and Laboratory Improvement grant 0836869 from the National Science Foundation to BW.

Received: 6 December 2011 Accepted: 31 May 2012

Published: 12 June 2012

\section{References}

1. Mangelsdorf DJ, Thummel C, Beato M, Herrlich P, Schütz G, Umesono K, Blumberg B, Kastner P, Mark M, Chambon P, Evans RM: The nuclear receptor superfamily: the second decade. Cell 1995, 83:835-839.

2. Blumberg B, Evans RM: Orphan nuclear receptors-new ligands and new possibilities. Genes Dev 1998, 12:3148-3155.

3. Kozlova T, Thummel CS: Steroid regulation of postembryonic development and reproduction in Drosophila. Trends Endocrinol Metab. 2000, 11:276-280.

4. Grasso LC, Hayward DC, Trueman JW, Hardie KM, Janssens PA, Ball EE: The evolution of nuclear receptors: evidence from the coral Acropora. Mol Phylogenet Evol. 2001, 21:93-102. 
5. Sluder AE, Mathews SW, Hough D, Yin VP, Maina CV: The nuclear receptor superfamily has undergone extensive proliferation and diversification in nematodes. Genome Res 1999, 9:103-120.

6. Enmark E, Gustafsson JA: Comparing nuclear receptors in worms, flies and humans. Trends Pharmacol Sci 2001, 22:611-615.

7. Maglich JM, Sluder A, Guan X, Shi Y, McKee DD, Carrick K, Kamdar K, Willson TM, Moore JT: Comparison of complete nuclear receptor sets from the human. Caenorhabditis elegans and Drosophila genomes. Genome Biol 2001, 2:29.

8. Antebi A: Nuclear hormone receptors in C. elegans. In The C. elegans Research Community, WormBook. doi:doi/10.1895/wormbook.1.64.1. http://www.wormbook.org.

9. Van Gilst M, Gissendanner CR, Sluder AE: Diversity and function of orphan nuclear receptors in nematodes. Crit Rev Eukaryot Gene Expr. 2002, 12:65-88.

10. Magner DB, Antebi A: Caenorhabditis elegans nuclear receptors: insights into life traits. Trends Endocrinol Metab. 2008, 19:153-160.

11. Taubert S, Ward JD, Yamamoto KR: Nuclear hormone receptors in nematodes: evolution and function. Mol Cell Endocrinol 2011, 334:48-55.

12. Haerty W, Artieri C, Khezri N, Singh RS, Gupta BP: Comparative analysis of function and interaction of transcription factors in nematodes: extensive conservation of orthology coupled to rapid sequence evolution. BMC Genomics. 2008, 9:399.

13. Dieterich C, Clifton SW, Schuster LN, Chinwalla A, Delehaunty K, Dinkelacker I, Fulton L, Fulton R, Godfrey J, Minx P, Mitreva M, Roeseler W, Tian H, Witte H, Yang SP, Wilson RK, Sommer RJ: The Pristionchus pacificus genome provides a unique perspective on nematode lifestyle and parasitism. Nat Genet 2008, 40:1193-1198

14. Borchert N, Dieterich C, Krug K, Schütz W, Jung S, Nordheim A, Sommer RJ, Macek B: Proteogenomics of Pristionchus pacificus reveals distinct proteome structure of nematode models. Genome Res 2010, 20:837-846.

15. Ghedin E, Wang S, Spiro D, Caler E, Zhao Q, Crabtree J, Allen JE, Delcher AL, Guiliano DB, Miranda-Saavedra D, Angiuoli SV, Creasy T, Amedeo P, Haas B, El-Sayed NM, Wortman JR, Feldblyum T, Tallon L, Schatz M, Shumway M, Koo H, Salzberg SL, Schobel S, Pertea M, Pop M White O, Barton GJ, Carlow CK, Crawford MJ, Daub J, Dimmic MW, Estes CF, Foster JM, Ganatra M, Gregory WF, Johnson NM, Jin J, Komuniecki R, Korf I, Kumar S, Laney S, Li BW, Li W, Lindblom TH, Lustigman S, Ma D, Maina CV, Martin DM, McCarter JP, McReynolds L, Mitreva M, Nutman TB, Parkinson J, Peregrín-Alvarez JM, Poole C, Ren Q, Saunders L, Sluder AE, Smith K, Stanke M, Unnasch TR, Ware J, Wei AD, Weil G, Williams DJ, Zhang Y, Williams SA, Fraser-Liggett C, Slatko B, Blaxter ML, Scott AL: Draft genome of the filarial nematode parasite Brugia malayi. Science 2007, 317:1756-1760.

16. Motola DL, Cummins CL, Rottiers V, Sharma KK, Li T, Li Y, Suino-Powell K, Xu $\mathrm{HE}$, Auchus RJ, Antebi A, Mangelsdorf DJ: Identification of ligands for DAF-12 that govern dauer formation and reproduction in C. elegans. Cell 2006, 124:1209-1223.

17. Committee Nuclear Receptors Nomenclature: A unified nomenclature system for the nuclear receptor superfamily. Cell 1999, 97:161-163.

18. Bonneton F, Chaumot A, Laudet V: Annotation of Tribolium nuclea receptors reveals an increase in evolutionary rate of a network controlling the ecdysone cascade. Insect Biochem Mol Biol. 2008, 38:416-429.

19. Strecker TR, Merriam JR, Lengyel JA: Graded requirement for the zygotic terminal gene, tailless, in the brain and tail region of the Drosophila embryo. Development 1988, 102:721-734.

20. Daniel A, Dumstrei $K$, Lengyel JA, Hartenstein V: The control of cell fate in the embryonic visual system by atonal, tailless and EGFR signaling. Development 1999, 126:2945-2954.

21. Monaghan AP, Bock D, Gass P, Schwäger A, Wolfer DP, Lipp HP, Schütz G: Defective limbic system in mice lacking the tailless gene. Nature 1997, 390:515-517.

22. Hollemann $\mathrm{T}$, Bellefroid $\mathrm{E}$, Pieler $\mathrm{T}$ : The Xenopus homologue of the Drosophila gene tailless has a function in early eye development. Development 1998, 125:2425-2432.

23. Yu RT, Chiang MY, Tanabe T, Kobayashi M, Yasuda K, Evans RM, Umesono K: The orphan nuclear receptor Tlx regulates Pax2 and is essential for vision. Proc Natl Acad Sci U S A 2000, 97:2621-2625.

24. Much JW, Slade DJ, Klampert K, Garriga G, Wightman B: The fax-1 nuclear hormone receptor regulates axon pathfinding and neurotransmitter expression. Development 2000, 127:703-712.
25. Milam AH, Rose L, Cideciyan AV, Barakat MR, Tang WX, Gupta N, Aleman TS, Wright AF, Stone EM, Sheffield VC, Jacobson SG: The nuclear receptor NR2E3 plays a role in human retinal photoreceptor differentiation and degeneration. Proc Natl Acad Sci U S A 2002, 99:473-478.

26. Wightman B, Ebert B, Carmean N, Weber K, Clever S: The C. elegans nuclear receptor gene fax- 1 and homeobox gene unc-42 coordinate interneuron identity by regulating the expression of glutamate receptor subunits and other neuron-specific genes. Dev Biol 2005, 287:74-85.

27. Sung C, Wong LE: Chang Sen LQ, Nguyen E, Lazaga N, Ganzer G, McNabb $\mathrm{SL}$, Robinow S: The unfulfilled/DHR51 gene of Drosophila melanogaster modulates wing expansion and fertility. Dev Dyn 2009, 238:171-182.

28. Lin S, Huang Y, Lee T: Nuclear receptor unfulfilled regulates axonal guidance and cell identity of Drosophila mushroom body neurons. PLOS One 2009, 4:e8392

29. Bates KE, Sung CS, Robinow S: The unfulfilled gene is required for the development of mushroom body neuropil in Drosophila. Neural Dev. 2010, 5:4.

30. DeMeo SD, Lombel RM, Cronin M, Smith EL, Snowflack DR, Reinert K, Clever S, Wightman B: Specificity of DNA-binding by the FAX-1 and NHR-67 nuclear receptors of Caenorhabditis elegans is partially mediated via a subclassspecific P-box residue. BMC Mol Biol 2008, 9:2.

31. Laudet V, Gronemeyer H: The Nuclear Receptors Facts Book. London: Academic Press; 2002.

32. Bertrand S, Brunet FG, Escriva H, Parmentier G, Laudet V, Robinson-Rechavi M: Evolutionary genomics of nuclear receptors: from twenty-five ancestral genes to derived endocrine systems. Mol Biol Evol 2004, 21:1923-1937.

33. Yu RT, McKeown M, Evans RM, Umesono K: Relationship between Drosophila gap gene tailless and a vertebrate nuclear receptor TIx. Nature 1994, 370:375-379

34. Bridgham JT, Eick GN, Larroux C, Deshpande K, Harms MJ, Gauthier ME, Ortlund EA, Degnan BM, Thornton JW: Protein evolution by molecular tinkering: diversification of the nuclear receptor superfamily from a ligand-dependent ancestor. PLOS Biol. 2010, 8:10.

35. Higgins D, Thompson J, Gibson T, Thompson JD, Higgins DG, Gibson TJ: CLUSTAL W: improving the sensitivity of progressive multiple sequence alignment through sequence weighting, position-specific gap penalties and weight matrix choice. Nucleic Acids Res 1994, 22:4673-4680.

36. Tamura K, Peterson D, Peterson N, Stecher G, Nei M, Kumar S: MEGA5: Molecular Evolutionary Genetics Analysis using Maximum Likelihood, Evolutionary Distance, and Maximum Parsimony Methods. Mol Biol Evol 2011, 28:2731-2739.

37. Bergsten J: A review of long-branch attraction. Cladistics 2005, 21:163-193.

38. Reitzel AM, Tarrant AM: Nuclear receptor complement of the cnidarian Nematostella vectensis: phylogenetic relationships and developmental expression patterns. BMC Evol Biol 2009, 9:230.

39. Velarde RA, Robinson GE, Fahrbach SE: Nuclear receptors of the honey bee: annotation and expression in the adult brain. Insect Mol Biol. 2006, 15:583-595

40. Cheng D, Xia Q, Duan J, Wei L, Huang C, Li Z, Wang G, Xiang Z: Nuclear receptors in Bombyx mori: insights into genomic structure and developmental expression. Insect Biochem Mol Biol. 2008, 38:1130-1137.

41. Tan A, Palli SR: Identification and characterization of nuclear receptors from the red flour beetle, Tribolium castaneum. Insect Biochem Mol Biol. 2008, 38:430-439.

42. Raška O, Kostrouchová V, Behenský F, Yilma P, Saudek V, Kostrouch Z, Kostrouchová M: SMED-TLX-1 (NR2E1) is critical for tissue and body plan maintenance in Schmidtea mediterranea in fasting/feeding cycles. Folia Biol (Praha). 2011, 57:223-231.

43. Howard-Ashby M, Materna SC, Brown CT, Chen L, Cameron RA, Davidson EH: Gene families encoding transcription factors expressed in early development of Strongylocentrotus purpuratus. Dev Biol 2006, 300:90-107.

44. Lowe CJ, Wu M, Salic A, Evans L, Lander E, Stange-Thomann N, Gruber CE, Gerhart J, Kirschner M: Anteroposterior patterning in hemichordates and the origins of the chordate nervous system. Cell 2003, 113:853-865.

45. Freeman RM, Wu M, Cordonnier-Pratt MM, Pratt LH, Gruber CE, Smith M, Lander ES, Stange-Thomann N, Lowe CJ, Gerhart J, Kirschner M: cDNA sequences for transcription factors and signaling proteins of the hemichordate Saccoglossus kowalevskii: efficacy of the expressed sequence tag (EST) approach for evolutionary and developmental studies of a new organism. Biol Bull 2008, 214:284-302. 
46. Rastinejad F, Wagner T, Zhao Q, Khorasanizadeh S: Structure of the RXR-RAR DNA-binding complex on the retinoic acid response element DR1. EMBO J 2000, 19:1045-1054.

47. Schwarz R, Dayhoff M: Matrices for detecting distant relationships. In Atlas of protein sequences. Edited by Dayhoff M. National Biomedical Research Foundation; 1979:353-358.

48. Sengupta $\mathrm{P}$, Colbert HA, Bargmann Cl: The C. elegans gene odr-7 encodes an olfactory-specific member of the nuclear receptor superfamily. Cell 1994, 79:971-980

49. King-Jones K, Thummel CS: Nuclear receptors-a perspective from Drosophila. Nat Rev Genet 2005, 6:311-323.

50. Parihar M, Minton RL, Flowers S, Holloway A, Morehead BE, Paille J, Gissendanner CR: The genome of the nematode Pristionchus pacificus encodes putative homologs of RXR/Usp and EcR. Gen Comp Endocrinol 2010, 167:11-17.

51. Simons SS: Structure and Function of the Steroid and Nuclear Receptor Lingand-Binding Domain. In Molecular Biology of Steroid and Nuclear Hormone Receptors. Edited by Freedman LP. Boston: Birkhauster; 1998:105-133.

52. Jones DT: GenTHREADER: an efficient and reliable protein fold recognition method for genomic sequences. J Mol Biol 1999, 287:797-815.

53. Jones DT: Protein secondary structure prediction based on positionspecific scoring matrices. J Mol Biol 1999, 292:195-202.

54. Chalfie M, Sulston JE, White JG, Southgate E, Thomson JN, Brenner S: The neural circuit for touch sensitivity in Caenorhabditis elegans. J Neurosci 1985, 5:956-964.

55. Schinkmann K, Li C: Localization of FMRFamide-like peptides in Caenorhabditis elegans. J Comp Neurol 1992, 316:251-260.

56. Wightman B, Baran R, Garriga G: Genes that guide growth cones along the C. elegans ventral nerve cord. Development 1997, 124:2571-2580.

57. Garriga G, Desai C, Horvitz HR: Cell interactions control the direction of outgrowth, branching and fasciculation of the HSN axons of Caenorhabditis elegans. Development 1993, 117:1071-1087.

58. de Rosny E, de Groot A, Jullian-Binard C, Borel F, Suarez C, Le Pape L, Fontecilla-Camps JC, Jouve HM: DHR51, the Drosophila melanogaster homologue of the human photoreceptor cell-specific nuclear receptor, is a thiolate heme-binding protein. Biochemistry 2008, 47:13252-13260.

59. Glass CK, Rosenfeld MG: The coregulator exchange in transcriptional functions of nuclear receptors. Genes Dev 2000, 14:121-141.

60. Blaustein JD: Minireview: Neuronal steroid hormone receptors: they're not just for hormones anymore. Endocrinology 2004, 145:1075-1081.

61. Sarin S, Antonio C, Tursun B, Hobert O: The C. elegans Tailless/TLX transcription factor nhr-67 controls neuronal identity and left/right asymmetric fate diversification. Development 2009, 136:2933-2944.

62. Gui H, Li ML, Tsai CC: A tale of tailless. Dev Neurosci 2011, 33:1-13.

63. Vermeirssen V, Barrasa MI, Hidalgo CA, Babon JA, Sequerra R, DoucetteStamm L, Barabási AL, Walhout AJ: Transcription factor modularity in a gene-centered $\mathrm{C}$. elegans core neuronal protein-DNA interaction network. Genome Res 2007, 17:1061-1071.

64. Kato M, Sternberg PW: The $C$. elegans tailless/TIx homolog nhr- 67 regulates a stage-specific program of linker cell migration in male gonadogenesis. Development 2009, 136:3907-3915.

65. Verghese E, Schocken J, Jacob S, Wimer AM, Royce R, Nesmith JE, Baer GM, Clever S, McCain E, Lakowski B, Wightman B: The tailless ortholog nhr-67 functions in the development of the C. elegans ventral uterus. Dev Biol 2011, 356:516-528

66. Arda HE, Taubert S, MacNeil LT, Conine CC, Tsuda B, Van Gilst M, Sequerra R, Doucette-Stamm L, Yamamoto KR, Walhout AJ: Functional modularity of nuclear hormone receptors in a Caenorhabditis elegans metabolic gene regulatory network. Mol Syst Biol 2010, 6:367.

67. Li S, Armstrong CM, Bertin N, Ge H, Milstein S, Boxem M, Vidalain PO, Han JD, Chesneau A, Hao T, Goldberg DS, Li N, Martinez M, Rual JF, Lamesch P, Xu L, Tewari M, Wong SL, Zhang LV, Berriz GF, Jacotot L, Vaglio P, Reboul J, HirozaneKishikawa T, Li Q, Gabel HW, Elewa A, Baumgartner B, Rose DJ, Yu H, Bosak S, Sequerra R, Fraser A, Mango SE, Saxton WM, Strome S, Van Den Heuvel S, Piano F, Vandenhaute J, Sardet C, Gerstein M, Doucette-Stamm L, Gunsalus KC, Harper JW, Cusick ME, Roth FP, Hill DE, Vidal M: A map of the interactome network of the metazoan C. elegans. Science 2004, 303:540-543.

68. Saitou N, Nei M: The neighbor-joining method: A new method for reconstructing phylogenetic trees. Mol Biol Evol 1987, 4:406-425.
69. Bryson K, McGuffin LJ, Marsden RL, Ward JJ, Sodhi JS, Jones DT: Protein structure prediction servers at University College London. Nucl. Acids Res 2005, 33(70):36-38.

70. Brenner S: The genetics of Caenorhabditis elegans. Genetics 1974, 77:71-94

71. Stiernagle T: Maintenance of C. elegans, WormBook. In The C. elegans Research Community; doi:10.1895/wormbook.1.101.1. http://www.wormbook.org.

72. Mello CC, Kramer JM, Stinchcomb D, Ambros V: Efficient gene transfer in C. elegans: extrachromosomal maintenance and integration of transforming sequences. EMBO J 1991, 10:3959-3970.

73. Heid CA, Stevens J, Livak KJ, Williams PM: Real time quantitative PCR Genome Res 1996, 6:986-994.

doi:10.1186/1471-2148-12-81

Cite this article as: Weber et al:: Analysis of C. elegans NR2E nuclear receptors defines three conserved clades and ligand-independent functions. BMC Evolutionary Biology 2012 12:81.

\section{Submit your next manuscript to BioMed Central and take full advantage of:}

- Convenient online submission

- Thorough peer review

- No space constraints or color figure charges

- Immediate publication on acceptance

- Inclusion in PubMed, CAS, Scopus and Google Scholar

- Research which is freely available for redistribution 